\title{
Correlation between plasma levels of carotenoid and oxidized low density lipoproteins: A short human intervention study
}

Tiziana Bacchetti ${ }^{1}$, Domenico Tullii ${ }^{2}$, Simona Masciangelo ${ }^{1}$, Francesca Brugè ${ }^{3}$, Sonia Silvestri ${ }^{3}$, Patrick Orlando ${ }^{3}$ Luca Tiano $^{3}$ and Gianna Ferretti $^{3 *}$

${ }^{1}$ Dipartimento di Scienze della Vita e dell'Ambiente, Università Politecnica delle Marche, 60100, Ancona, Italia

${ }^{2}$ Italsur s.rl., Notaresco (TE), Italia

${ }^{3}$ Dipartimento di Scienze Cliniche Specialistiche e Odontostomatologiche, Università Politecnica delle Marche,60100, Ancona, Italia

\begin{abstract}
The development of vegetable functional food products that provide benefits beyond their traditional nutritional value raised increasing interest. In fact several studies have shown that diet plays a role in the development of human diseases associated with oxidative damage (diabetes, cardiovascular disease and metabolic syndrome). Aim of the study was to evaluate the effects of daily intake of $300 \mathrm{~g}$ of a frozen vegetable product containing red and green spinach, red and green chicory, red and green leaf chard (Italsur srl Notaresco, Italy) on plasma lipids and oxidized low density lipoproteins (ox-LDL). Furthermore, the bioavailability of lutein and $\beta$-carotene was investigated. The study included $n=49$ healthy volunteers (age ranged from 23 to 73 year), who consumed a portion of the vegetable product ( $300 \mathrm{~g}$ ) every day for 2 weeks. The significant increase of plasma lutein and $\beta$-carotene after vegetable mix consumption for 2 weeks demonstrated that these phytonutrients are highly bioavailable. A significant reduction of plasma levels of total cholesterol (TC) and LDL-cholesterol (LDL-C) was observed after dietary intervention. The results demonstrated a significant decrease in plasma concentration of ox-LDL after treatment. Evaluation of ox-LDL represents a useful biochemical marker of lipid peroxidation; therefore the results demonstrated a decrease of lipid peroxidation of lipoproteins associated with the consumption of vegetable product. A significant negative correlation has been established between levels of plasma lutein and levels of ox-LDL before and after daily intake of the vegetable product. These results suggest that lutein may play a role in the protective effect against oxidation of LDL. In conclusion the increase of plasma carotenoids after dietary treatment for two weeks is associated with a protective effect against lipid peroxidation of lipoproteins.
\end{abstract}

\section{Introduction}

The frozen ready-to-eat vegetables market has been growing and deserves increasing attention due to modifications of lifestyle and changes of dietary habits. Accurate selection of vegetables can result in convenient, healthy and appealing products, which may contain interesting bioactive compounds. Among vegetable foods that could be defined as functional foods there are pigmented vegetables such red spinach, green spinach, red chicory and red chard. Previous studies have demonstrated that they contain bioactive molecules and phytochemicals (polyphenols and carotenoids), vitamins (vitamin $\mathrm{C}$, folate, and provitamin A), minerals (potassium, calcium, and magnesium) and fibers [1-5]. However their biological effects have been manly investigated in vitro and in model animals [6-10].

Among phytonutrients, carotenoids have been widely investigated for their protective role against lipid peroxidation. In fact plasma carotenoid levels are associated with low density lipoproteins in particular [11]. The correlation between dietary intake of carotenoids and plasma carotenoid levels has been previously demonstrated [1218]. Therefore the increase in plasma level of carotenoids after dietary intake of vegetable has been suggested as a useful nutritional marker of their bioavailability in human subjects. An increased plasma total antioxidant capacity has also been associated with a consumption of vegetable antioxidants $[13,19,20]$. The bioavailability of bioactive nutrients is modulated by different factors such as chemical composition of vegetable and processing [19,21,22].
In order to evaluate the nutritional properties of a ready to eat frozen product and the biovailability of the main bioactive molecules, we investigated the plasma levels of carotenoids and antioxidant potential after intake of a experimental ready-to-eat product containing pigmented vegetables that are rich sources of polyphenols, carotenoids and other phytochemicals. Therefore we enrolled 48 volunteers whose diet was supplemented for two weeks with a daily portion of the vegetable product Moreover we studied the effect of the intake of the product on the markers of cardiovascular disease such as plasma lipid profile and levels of oxidized LDL.

\section{Materials and methods}

\section{Subjects}

The study was conducted during September-November 2012. The inclusion criteria for subjects were: not taking vitamins, minerals,

Correspondence to: Gianna Ferretti, Dipartimento di Scienze Cliniche Specialistiche e Odontostomatologiche, Università Politecnica delle Marche,60100, Via Brecce Bianche, 60131 Ancona, Italia; E-mail: g.ferretti@univpm.it

Key words: pigmented vegetable, functional foods, oxidized-LDL, plasma lipids, carotenoids, antioxidant

Received: February 20, 2016; Accepted: March 22, 2016; Published: March 25 2016 
or other types of supplements during the previous two months; nosmoking; BMI within the normal range according to the World Health Organization criteria $\left(18.5-25 \mathrm{~kg} / \mathrm{m}^{2}\right)$ and normal biochemical and haematological profile (serum cholesterol $<6.8 \mathrm{mmol} / \mathrm{L}$, serum triacylglycerols $<2.8 \mathrm{mmol} / \mathrm{L}$, glucose $<6.11 \mathrm{mmol} / \mathrm{L}$ ).

The exclusion criteria were: diagnosed diseases such as allergies, cancer, diabetes, obesity, hypertension, mental diseases, gastrointestinal or renal diseases, as well as intake of drugs related to these pathologies, alcohol consumption $>30 \mathrm{~g} /$ day, vegetarian diet. None of the female subjects was pregnant or lactating. Volunteers were recruited in the Polytechnic University of Marche (UNIVPM), Italy.

Forty-eight subjects followed the diet, 22 of them (45.8\%) were males. The median age was 40.5 years ( $1^{\text {st }}-3^{\text {rd }}$ quartile: $36-47$ years) and median BMI $23.6 \mathrm{~kg} / \mathrm{m}^{2}\left(1^{\text {st }}-3^{\text {rd }}\right.$ quartile: $\left.21.8-26.4 \mathrm{~kg} / \mathrm{m}^{2}\right)$. The mean plasma lipid measurements for the subjects are summarized in Table 1.

\section{Intervention study}

The intervention phase consisted of a 2-week period which included daily consumption of a portion (300 g) of the vegetable frozen product supplied by Italsur srl (Notaresco, Teramo,Italia). The vegetable frozen product contains the same proportions of red spinach (Spinacia oleracea), green spinach (Spinacia oleracea), red chicory and green chicory and a lower percentage of green chard (Beta vulgaris L. var. cicla) and red chard (Beta vulgaris L. var. cicla). Macronutrients contained in a portion of the final product were evaluated [23]. Water-soluble vitamins were quantified by highperformance liquid chromatography/electrospray ionization-mass spectrometry [24]. Carotenoids were analyzed using high performance liquid chromatography (HPLC) [25]. Total polyphenols were evaluated following Xu et al. [26]. Total antioxidant potential was evaluated by ORAC assay [4]. Table 2 shows the percentage of the energy, macro and micronutrients found in the vegetable product.

The product was consumed after cooking for 15 minutes with 2 tablespoons extra virgin olive oil. Intake of the vegetable product was included in the normal daily diet and no specific time of consumption or accompanying meal was established. Subjects were recommended to maintain their habitual dietary intake (especially as regard to their consumption of a provided list of foods with high carotenoid, polyphenol and vitamin C contents) and their usual physical activity or other lifestyle habits. Moreover, they were requested to record any sign of illnesses, medications, and any deviations from their experimental diets. No subject was reported to have side effects and thus, no one

Table 1. Plasma lipid profile, levels of ox-LDL and total antioxidant capacity subjects in plasma of LDL in plasma of subjects at baseline and after 2 week period which include a daily portion of the ready-to-eat product containing pigmented vegetables. (Data are shown as mean \pm standard deviation). A p $<0.05$ was considered statistically significant.

\begin{tabular}{|l|c|c|c|}
\hline & $\begin{array}{c}\text { Baseline } \\
(\mathbf{n}=\mathbf{4 9})\end{array}$ & $\begin{array}{c}\text { After 2-weeks } \\
(\mathbf{n}=\mathbf{4 9})\end{array}$ & P value \\
\hline TC $(\mathrm{mmol} / \mathrm{L})$ & $4.87 \pm 0.56$ & $4.55 \pm 0.52$ & $\mathrm{p}<0.001$ \\
\hline LDL-C $(\mathrm{mmol} / \mathrm{L})$ & $2.80 \pm 0.56$ & $2.53 \pm 0.52$ & $\mathrm{p}<0.001$ \\
\hline HDL-C (mmol/L) & $1.65 \pm 0.28$ & $1.65 \pm 0.30$ & $\mathrm{p}=0.5$ \\
\hline TG (mmol/L) & $0.91 \pm 0.41$ & $0.87 \pm 0.37$ & $\mathrm{p}=0.06$ \\
\hline $\begin{array}{l}\text { Fasting glucose } \\
\text { (mmol/L) }\end{array}$ & 4.880 .43 & $4.83 \pm 0.31$ & $\mathrm{p}=0.07$ \\
\hline $\begin{array}{l}\text { Total antioxidant } \\
\text { capacity (mmol TE/L) }\end{array}$ & $14634 \pm 3492$ & $16218 \pm 3834$ & $\mathrm{p}<0.001$ \\
\hline ox-LDL (U/L) & $41.7 \pm 16.1$ & $32.6 \pm 12.2$ & $\mathrm{p}<0.001$ \\
\hline ox-LDL/LDL-C (U/mmol) & $15.2 \pm 5.6$ & $13.2 \pm 5.2$ & $\mathrm{p}<0.001$ \\
\hline
\end{tabular}

Table 2. Macronutrients, vitamins and phytochemicals in a portion (300 g) of vegetable product containing red and green spinach, red and green chicory, red and green leaf chard (Italsur srl Notaresco, Italy). (Data are reported as mean \pm standard deviation of data from analyses carried out in samples from different batch and different years (2011 and 2013)).

\begin{tabular}{|l|c|}
\hline & $\begin{array}{c}\text { Composition of a portion of } \\
\text { vegetable product (300 g) }\end{array}$ \\
\hline Energy ( kcal) & $18 \pm 2$ \\
\hline Protein (g) & $7.8 \pm 1.1$ \\
\hline Carbohydrate(g) & $11.0 \pm 2.2$ \\
\hline Fiber(g) & $8.5 \pm 0.18$ \\
\hline Fat(g) & $0.63 \pm 0.01$ \\
\hline Saturated fatty acids(g) & $0.15 \pm 0.01$ \\
\hline Monounsaturated fatty acids (g) & $0.06 \pm 0.01$ \\
\hline Vitamin C (mg) & $85 \pm 3.7$ \\
\hline Folate(mg) & $0.33 \pm 2.7$ \\
\hline Alpha-tocopherol(mg) & $3.9 \pm 0.30$ \\
\hline Niacin(mg) & $1.2 \pm 0.05$ \\
\hline Retinol(mg) & $3.2 \pm 0.20$ \\
\hline Riboflavin(mg) & $0.27 \pm 0.03$ \\
\hline Thiamine(mg) & $0.18 \pm 0.01$ \\
\hline Total Polyphenols & $530 \pm 82$ \\
\hline Caffeic acid (mg) & $80.1 \pm 3.7$ \\
\hline Chlorogenic acid (mg) & $18.2 \pm 1.5$ \\
\hline Coumaric acid (mg) & $3.4 \pm 0.34$ \\
\hline Ferulic acid (mg) & $2.3 \pm 0.11$ \\
\hline Betacyanin (mg) & $26.7 \pm 1.5$ \\
\hline Luteolin (mg) & $4.7 \pm 0.9$ \\
\hline Kaempferol (mg) & $1.23 \pm 0.17$ \\
\hline Quercetin (mg) & $1.91 \pm 0.11$ \\
\hline Isorhamnetin (mg) & $1.32 \pm 0.02$ \\
\hline$\beta$-carotene (mg) & $11.1 \pm 0.8$ \\
\hline Zeaxanthin (mg) & $0.7 \pm 0.1$ \\
\hline Lutein (mg) & \\
\hline Total ORAC (mmol(TE)) & \\
\hline & \\
\hline
\end{tabular}

dropped out during the experimental period. At the beginning of the intervention (baseline, T0) and at the end (after 2 weeks, T15), fasting blood samples were collected. The study was performed in accordance with the Helsinki Declaration of Human Studies and approved by the Ethical Committee of the "Azienda Ospedaliero-Universitaria Ospedali Riuniti” Ancona (Italy) (Protocol number 211525). All participants signed an informed consent document.

\section{Analytical determinations}

At the beginning of the study and after two weeks of dietary treatment, fasting blood samples $(10 \mathrm{~mL})$ were collected from each subject by venipuncture from the antecubital vein: $5 \mathrm{~mL}$ were placed in heparin tubes for haematological measurements, while $5 \mathrm{~mL}$ were placed in tubes without any anticoagulant and centrifuged at $1500 \mathrm{~g}$ for $10 \mathrm{~min}$ at $4^{\circ} \mathrm{C}$ for serum separation. Plasma and serum aliquots were prepared and stored at $-80^{\circ} \mathrm{C}$ until analysis. Analyses did not commence until the full intervention study was completed and all samples from each subject were analysed within one batch to reduce interbatch variation.

\section{Plasma lipids and glycaemia}

Serum glucose, triacylglycerols (TG), total cholesterol (TC), high density lipoprotein cholesterol (HDL-C) were analyzed by commercial kits (Chemadiagnostica, Jesi, Italy). Low density lipoprotein cholesterol (LDL-C) was calculated by the Friedewald formula. 


\section{Plasma carotenoids}

Carotenoids ( $\beta$-carotene and lutein) were quantified in plasma of subjects by high-performance liquid chromatography (HPLC) system, using a single dilution step after extraction with propanol $(1: 5, \mathrm{v} / \mathrm{v})$ and vigorous vortexing of $250 \mu \mathrm{L}$ of extraction mixture. This mix was centrifuged for $2 \mathrm{~min}$ at $20,000 \mathrm{~g}$ at $4^{\circ} \mathrm{C}$. Forty microlitres of super natant were injected into the HPLC with electrochemical detector (ECD) by Shiseido (Tokyo, Japan), using a pre-separation concentrating column $50 \times 2.0 \mathrm{~mm}$ ID $5 \mu \mathrm{m}$, separation C18 column $150 \times 2.0 \mathrm{~mm}$ ID $3 \mu \mathrm{m}$, and a post-separation reducing column CQR $20 \times 2.0 \mathrm{~mm}$, all from Shiseido. For each carotenoid quantified, two mobile phases were used. Mobile phase 1 for loading and concentrating the sample (50 $\mathrm{mM}$ sodium perchlorate in methanol/water $95: 5, \mathrm{v} / \mathrm{v}$ ) was the same for both molecules, while mobile phase 2 was $50 \mathrm{mM}$ sodium perchlorate in methanol/isopropanol $(80: 20, \mathrm{v} / \mathrm{v})$ for lutein and $50 \mathrm{mM}$ sodium perchlorate in methanol/isopropanol $(98: 2, \mathrm{v} / \mathrm{v})$ for $\beta$-carotene. Moreover, flow rate was $200 \mu \mathrm{L} / \mathrm{min}$ for phase 1 in both analyses. Flow rates for phase 2 were 300 and $80 \mu \mathrm{L} / \mathrm{min}$ for $\beta$-carotene and lutein, respectively. Total chromatographic run times and retention times were $24 \mathrm{~min} / 12.3 \mathrm{~min}$ for $\beta$ carotene and $21 \mathrm{~min} / 9.8$ $\min$ for lutein [12].

\section{Plasma total antioxidant capacity (PAT)}

Plasma total antioxidant capacity (PAT) was measured using oxygen radical absorbance capacity (ORAC) adapted for semiautomated measurement on a 96-well microplate reader (Synergy HT; BioTek, Winooski, VT, USA) [27].

\section{Markers of lipid peroxidation}

In-vivo oxidized LDL were determined in plasma by a sandwich ELISA procedure using the murine monoclonal antibody mAB-4E6 as the capture antibody, and a peroxidase conjugated antibody against oxidized apolipoprotein B bound to the solid phase (ox-LDL, Mercodia $\mathrm{AB}$, Uppsala, Sweden). Intra and inter-assay CVs were $2.82 \%$ and $7.29 \%$, respectively. As LDL-C is considered a major determinant of absolute ox-LDL levels, plasma values of ox-LDL (U/L) were adjusted by the plasma levels of LDL-C $(\mathrm{mmol} / \mathrm{L})$ by calculating their ratio (units of ox-LDL per mmol of LDL-C), in agreement with Zuliani et al. [28].

\section{Statistical analysis}

Mean value, standard deviation (DS), and mean standard error (SEM) were calculated. By using Student $\mathrm{T}$ test, we evaluated the significance of differences between mean values at study entry and following treatment. A p of 0.05 was considered statistically significant. Pearson correlation coefficients and their significance levels were calculated for linear regression analysis.

\section{Results}

Macronutrients and micronutrients contained in the frozen readyto-eat product containing pigmented vegetables are summarized in Table 2. A portion of the product $(300 \mathrm{~g})$ contains $8.5 \pm 0.18 \mathrm{~g}$ and provides $34 \%$ of recommended daily intake of fiber $(25 \mathrm{~g} /$ day $)$. It contains high levels of vitamin C $(85 \pm 3.7 \mathrm{mg})$ and folate $(0.33 \pm 2.7$ $\mathrm{mg}$ ); a portion provides more than $100 \%$ of recommended dietary allowances (RDA) of both vitamins (Commission Directive 2008/100/ EC). The levels of carotenoids were $11.1 \pm 0.8 \mathrm{mg}$ of $\beta$-carotene and $29.6 \pm 0.30 \mathrm{mg}$ of lutein (Table 2). As shown in Table 2, among polyphenols, phenolics acids and flavonols are the main components in the vegetable product. Anthocyanins and flavones have also been identified (Table 2). Using ORAC assay to evaluate total antioxidant capacity, the product ranks highest among vegetables [29]. In fact a portion of the frozen product provides $5.8 \pm 0.1 \mathrm{mmol} / \mathrm{TE}$.

\section{Plasma lipids}

Subjects at baseline were characterized by normal levels of the lipid profile (Table 1). A significant decrease occurred in TC, LDL-c after 15 days of diet are presented in Table 1. No significant difference was found in the absolute variation of HDL cholesterol levels and triacylglicerol levels (Table 1).

\section{Carotenoids}

Basal levels of lutein ranged from $0.16 \mu \mathrm{g} / \mathrm{mL}$ to $0.75 \mu \mathrm{g} / \mathrm{mL}$ and basal levels of $\beta$-carotene ranged from $0.07 \mu \mathrm{g} / \mathrm{mL}$ to $0.53 \mu \mathrm{g} / \mathrm{mL}$, the median values are in agreement with previous studies by us and other authors (Figure 1) [13,30].

Figure 1 shows the variation in plasma concentrations of lutein and $\beta$-carotene after daily intake of the experimental product compared with baseline. A significant increase of plasma carotenoids (lutein and beta-carotene) was found after 15 days of supplemented diet $(\mathrm{p}<0.001)$.

\section{Levels of oxidized LDL and total antioxidant properties}

Plasma levels of ox-LDL were determined as biomarkers of lipid peroxidation during the study. The basal levels of ox-LDL were similar to those reported in previous studies by us and other studies on healthy subjects (Table 1) [13, 28]. Significant decrease of the plasma levels oxLDL and ox-LDL/LDL ratio was found after 15 days of supplemented diet (Table 1).

\section{Relationship between plasma carotenoids and markers of lipid peroxidation}

As shown in Figure 2 a significant negative correlation has been established between levels of plasma lutein and levels of ox-LDL $(\mathrm{r}=0.59, \mathrm{n}=98, \mathrm{p}<0.001)$ and ox-LDL/LDL-C $(\mathrm{r}=0.61, \mathrm{n}=98, \mathrm{p}<0.001)$ before and after daily intake of "Mix of chard, chicory and spinach"; no significant correlations were observed with plasma levels of $\beta$-carotene and levels of markers of lipid peroxidation.

\section{Discussion}

The phytochemical composition of pigmented vegetables has been

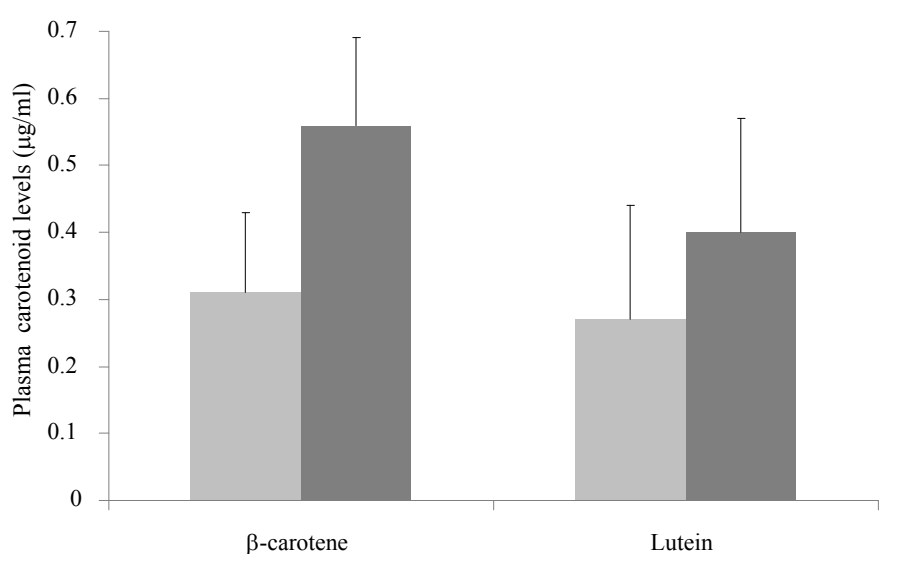

Figure 1. Levels of carotenoids (beta carotene and lutein) in plasma of subjects at baseline $(\diamond)$ and after 2 weeks period $(\diamond)$ which include a daily portion of the ready-to-eat product containing pigmented vegetables.

$* \mathrm{p}<0.001$ vs. $\beta$-carotene levels in subjects at baseline; $* * \mathrm{p}<0.001$ vs. lutein levels in subjects at baseline. 


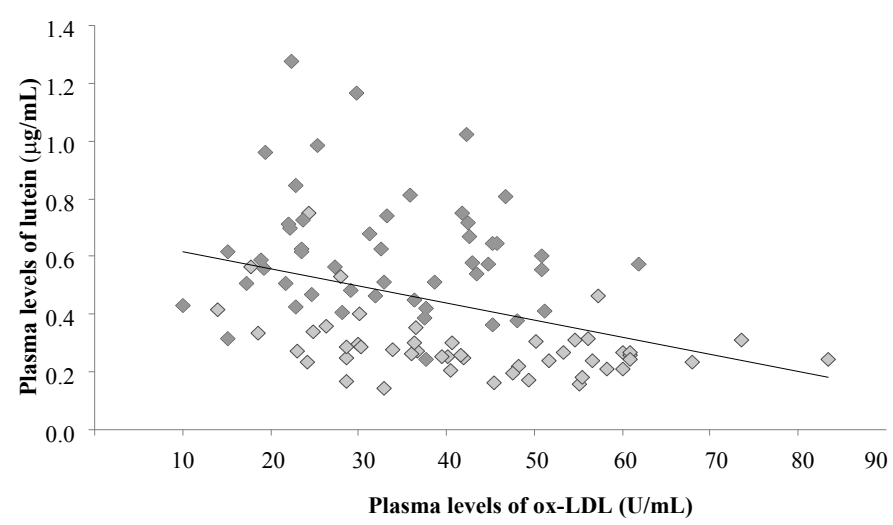

Figure 2. Correlation between levels of lutein and of oxidized LDL in plasma of subjects at baseline $(\diamond)$ and after 2 weeks period which included a daily portion of the ready-to-eat product containing pigmented vegetables $(\diamond)$.

previously investigated [1-5]. However the biological effect on human subjects has not been previously studied.

A portion of the vegetable product contains about $30 \mathrm{mg}$ lutein and $11 \mathrm{mg}$ beta carotene. Serum carotenoid concentration increased after 2 weeks, beta-carotene concentration by $56 \%$ and lutein concentration by $94.5 \%$ compared with baseline. These data demonstrated that these phytonutrients in the product are bioavailable. In our previous study we have demonstrated that the daily intake for two weeks of a portion of the vegetable combination of black and red cabbage containing 1 $\mathrm{mg}$ lutein and $0.6 \mathrm{mg} \beta$-carotene, increased plasma $\beta$-carotene and lutein concentration by 80 and $204 \%$, respectively compared with the baseline [13]. Other authors have demonstrated that three weeks of intake of $9.3 \mathrm{mg}$ of beta-carotene from spinach products increased serum concentration by 53\% [31]. Martinez-Thomas et al. [32] have confirmed an increase of beta-carotene by $114 \%$ after three weeks 3.9 $\mathrm{mg}$ of beta-carotene contained in a fruit and vegetable soup. The interrelationship of different carotenoids present in food matrix affects carotenoid absorption and could explain the different percentage increase. In particular it is well known that lutein modulates betacarotene bioavailability [33].

Using the evaluation of the total antioxidant capacity, that represents a suitable biochemical parameter for assessing the overall antioxidant status, we demonstrated a significant increase. Our results demonstrated also that that the daily consumption of the product for 2 weeks is associated with a significant reduction of total-cholesterol and LDL-C in absence of changes of HDL-C and TG levels.

A portion of the vegetable product contains $8.5 \mathrm{~g}$ of fibers and about a third $(2.5 \mathrm{~g})$ is represented by soluble fiber. Extensive research has shown that fibres play an important role in cholesterol metabolism by decreasing plasma TC and LDL-C, as demonstrated in a meta-analysis [34]. In general, most soluble fibers lower plasma total cholesterol more efficiently than water-insoluble fibers by decreasing LDL cholesterol without significantly affecting the HDL-C and TG levels [34]. Other phytochemicals contained in the product such as polyphenols could contribute to the LDL cholesterol lowering effect. This hypothesis is supported by previous studies, in-vivo, which has demonstrated that diets naturally rich in polyphenols improve plasma lipid profile [3537]. Moreover, in vitro studies, have shown that individual polyphenols such anthocyanins, quercetin, kaempferol and luteolin are able to modulate cholesterol absorption [38,39] and lipid synthesis [40].

The decrease of oxidized LDL could be related to the modifications of carotenoid and/or other phytochemicals as suggested by previous human studies [12-17]. By the product analysis it was evidenced a high content of vitamin C. Previous studies have observed an inverse correlation between vitamin $\mathrm{C}$ concentrations and 8-epiPGF2 concentrations in subjects at baseline and after 2 week of supplementation with the vegetable soup [41,42], moreover there is convincing evidence that vitamin $\mathrm{C}$ is a strong inhibitor of LDL oxidation [43], a recognized factor in the pathogenesis and progression of human atherosclerosis, by scavenging free radicals and other reactive species, and preventing their interaction to oxidize LDL [43]. All the aforementioned nutrients may have synergistically contributed to the protective effect associated with consumption of the vegetable product.

The statistical analysis of the effect of dietary intervention on biochemical parameters has demonstrated variability. A significant higher increase of lutein and $\beta$-carotene levels was observed in females. Moreover, subjects with values of TC, HDL-c, triacylglycerol, ox-LDL and ox-LDL/LDL ratio, over the median, had a higher decrease of the dependent variable. This variability in response must be associated with genetic or other characteristics of the individual [44].

Diet is considered the cornerstone for the prevention of age-related diseases, and a low-fat diet has been considered for decades as the most suitable alternative to achieve this goal. However, mounting evidence supports the efficacy of other alternatives, such as the Mediterranean diet and intake of foods rich in antioxidants and phytochemicals [45].

In conclusion the synergistic effects of phytochemicals (dietary fibers, polyphenols, carotenoids) present in the frozen ready to eat product could be responsible for the protective effects and benefits observed could be attributed to the complex mixture of phytochemicals present in whole foods. High levels of LDL-cholesterol and of oxidized LDL are biochemical markers for atherosclerosis [46,47]. Therefore we suggest that products rich in carotenoids and other phytochemicals could be inserted in dietary intervention aimed to prevent cardiovascular diseases and their complications.

Despite dietary health effects are influenced by genetic factors [44], an accurate selection of pigmented vegetable results in palatable, convenient and healthy product with physiological effects on plasma lipids and lipid peroxidation.

\section{Authors' contribution}

All authors contributed to the intellectual development of this work and approved the final manuscript. TB and GF were responsible for the experimental design, coordination of research and preparation of the manuscript; TB and SM carried out evaluations of plasma biochemical parameters (plasma lipids, markers of lipid peroxidation) and participated in the preparation of the manuscript; D.T. was actively involved in the chemical and agronomic investigation of plant species used to make the frozen product; LT, FB, SS and PO carried out evaluations of plasma carotenoids and contributed to the preparation of the manuscript.

\section{References}

1. Chu YF, Sun J, Wu X, Liu RH (2002) Antioxidant and antiproliferative activities of common vegetables. J Agric Food Chem 50: 6910-6916. [Crossref]

2. Kugler F, Stintzing FC, Carle R (2004) Identification of betalains from petioles of differently colored Swiss chard (Beta vulgaris L. ssp. cicla [L.] Alef. Cv. Bright Lights) by high-performance liquid chromatography-electrospray ionization mass spectrometry. J Agric Food Chem 52: 2975-2981.

3. Ninfali P, Bacchiocca M, Antonelli A, Biagiotti E, Di Gioacchino AM, et al. (2007) 
Characterization and biological activity of the main flavonoids from Swiss Chard (Beta vulgaris subspecies cycla). Phytomedicine 14: 216-221. [Crossref]

4. Ninfali P, Bacchiocca M (2003) Polyphenols and antioxidant capacity of vegetables under fresh and frozen conditions. J Agric Food Chem 51: 2222-2226. [Crossref]

5. Proteggente AR, Pannala AS, Paganga G, Van Buren L, Wagner E, et al. (2002) The antioxidant activity of regularly consumed fruit and vegetables reflects their phenolic and vitamin C composition. Free Radic Res 36: 217-233. [Crossref]

6. Ko SH, Park JH, Kim SY, Lee SW, Chun SS, et al. (2014) Antioxidant Effects of Spinach (Spinacia oleracea L.) Supplementation in Hyperlipidemic Rats. Prev Nutr Food Sci 19: 19-26. [Crossref]

7. Lee JH, Son CW, Kim MY, Kim MH, Kim HR, et al. (2009) Red beet (Beta vulgaris L.) leaf supplementation improves antioxidant status in $\mathrm{C} 57 \mathrm{BL} / 6 \mathrm{~J}$ mice fed high fat high cholesterol diet. Nutr Res Pract 3: 114-121. [Crossref]

8. Kim MY, Cheong SH, Kim MH, Son C, Yook HS, et al. (2009) Leafy vegetable mix supplementation improves lipid profiles and antioxidant status in C57BL/6J mice fed a high fat and high cholesterol diet. J Med Food 12: 877-884. [Crossref]

9. Lavelli V (2008) Antioxidant activity of minimally processed red chicory (Cichorium intybus $L$.) evaluated in xanthine oxidase-, myeloperoxidase-, and diaphorase-catalyzed reactions. J Agric Food Chem 56: 7194-7200.

10. Bhatia AL, Jain M (2004) Spinacia oleracea L. protects against gamma radiations: study on glutathione and lipid peroxidation in mouse liver. Phytomedicine 11: 607-615. [Crossref]

11. Wang W, Connor SL, Johnson EJ, Klein ML, Hughes S, et al. (2007) Effect of dietary lutein and zeaxanthin on plasma carotenoids and their transport in lipoproteins in agerelated macular degeneration. Am J Clin Nutr 85: 762-769. [Crossref]

12. Barona J, Jones JJ, Kopec RE, Comperatore M, Andersen C, et al. (2012) A Mediterranean-style low-glycemic-load diet increases plasma carotenoids and decreases LDL oxidation in women with metabolic syndrome. J Nutr Biochem 23: 609-615. [Crossref]

13. Bacchetti T, Tullii D, Masciangelo S, Gesuita R (2014) Effect of black and red cabbage on plasma carotenoid levels, lipid profile and oxidized low density lipoprotein. J Funct Foods 8: 128-137.

14. Beck J, Ferrucci L, Sun K, Fried LP (2008) Circulating oxidized low-density lipoproteins are associated with overweight, obesity, and low serum carotenoids in older community-dwelling women. Nutrition 24: 964-968.

15. Gaskins AJ, Rovner AJ, Mumford SL, Yeung E, Browne RW, et al. (2010) Adherence to a Mediterranean diet and plasma concentrations of lipid peroxidation in premenopausal women. Am J Clin Nutr 92: 1461-1467. [Crossref]

16. Haegele AD, Gillette C, O’Neill C, Wolfe P (2000) Plasma xanthophyll carotenoids correlate inversely with indices of oxidative DNA damage and lipid peroxidation. Cancer Epidem Biomar 9: 421-425.

17. Kay CD, Gebauer SK, West SG, Kris-Etherton PM (2010) Pistachios increase serum antioxidants and lower serum oxidized-LDL in hypercholesterolemic adults. J Nutr 140: 1093-1098. [Crossref]

18. Thompson HJ, Heimendinger J, Gillette C, Sedlacek SM, Haegele A, et al. (2005) In vivo investigation of changes in biomarkers of oxidative stress induced by plant food rich diets. J Agric Food Chem 53: 6126-6132. [Crossref]

19. Cao G, Booth SL, Sadowski JA, Prior RL (1998) Increases in human plasma antioxidant capacity after consumption of controlled diets high in fruit and vegetables. Am J Clin Nutr 68: 1081-1087. [Crossref]

20. Root MM, McGinn MC, Nieman DC, Henson DA, Heinz SA, et al. (2012) Combined fruit and vegetable intake is correlated with improved inflammatory and oxidant status from a cross-sectional study in a community setting. Nutrients 4: 29-41. [Crossref]

21. Cilla A, Alegría A, de Ancos B, Sánchez-Moreno C, Cano MP, et al. (2012) Bioaccessibility of tocopherols, carotenoids, and ascorbic acid from milk- and soybased fruit beverages: influence of food matrix and processing. J Agric Food Chem 60: 7282-7290. [Crossref]

22. Riso P, Brusamolino A, Scalfi L, Porrini M (2004) Bioavailability of carotenoids from spinach and tomatoes. Nutr Metab Cardiovasc Dis 14: 150-156. [Crossref]

23. Baldini M, Forti S, Orsatti A, Ulivieri FM, Airaghi L, et al. (2014) Bone disease in adult patients with $\hat{\mathrm{I}}^{2}$-thalassaemia major: a case-control study. Intern Emerg Med 9: 59-63. [Crossref]

24. Chen Z, Chen B, Yao SZ (2006) High-performance liquid chromatography/electrospray ionization-mass spectrometry for simultaneous determination of taurine and 10 watersoluble vitamins in multivitamin tablets. Anal Chim Acta 569: 169-175.

25. Guvenc M, Guvenc H, Karatas F, Aygun AD, Bektas S (2002) Low levels of selenium in miscarriage. J Trace Elem Exp Med 15: 97-101.

26. Xu BJ, Chang SKC (2009) Total Phenolic, Phenolic Acid, Anthocyanin, Flavan-3-ol, and Flavonol Profiles and Antioxidant Properties of Pinto and Black Beans (Phaseolus vulgaris L.) as Affected by Thermal Processing. J Agr Food Chem 57: 4754-4764.

27. Fernández-Pachón MS, Villaño D, Troncoso AM, García-Parrilla MC (2005) Antioxidant capacity of plasma after red wine intake in human volunteers. $J$ Agric Food Chem 53: 5024-5029. [Crossref]

28. Zuliani G, Morieri ML, Volpato S, Vigna GB, Bosi C, et al. (2013) Determinants and clinical significance of plasma oxidized LDLs in older individuals. A 9 years follow-up study. Atherosclerosis 226: 201-207. [Crossref]

29. Wu X, Beecher GR, Holden JM, Haytowitz DB, Gebhardt SE, et al. (2004) Lipophilic and hydrophilic antioxidant capacities of common foods in the United States. J Agric Food Chem 52: 4026-4037. [Crossref]

30. Al-Delaimy WK, van Kappel AL, Ferrari P, Slimani N (2004) Plasma levels of six carotenoids in nine European countries: report from the European Prospective Investigation into Cancer and Nutrition (EPIC). Public Health Nutr 7: 713-722.

31. Castenmiller JJ, Lauridsen ST, Dragsted LO, van het Hof KH, Linssen JP, et al. (1999) beta-carotene does not change markers of enzymatic and nonenzymatic antioxidant activity in human blood. J Nutr 129: 2162-2169. [Crossref]

32. Martinez-Tomas R, Larque E, Gonzalez-Silvera D, Sanchez-Campillo M (2011) Effect of the consumption of a fruit and vegetable soup with high in vitro carotenoid bioaccessibility on serum carotenoid concentrations and markers of oxidative stress in young men. Eur J Nutr 51: 231-239.

33. Kostic D, White WS, Olson JA (1995) Intestinal absorption, serum clearance, and interactions between lutein and beta-carotene when administered to human adults in separate or combined oral doses. Am J Clin Nutr 62: 604-610. [Crossref]

34. Brown L, Rosner B, Willett WW, Sacks FM (1999) Cholesterol-lowering effects of dietary fiber: a meta-analysis. Am J Clin Nutr 69: 30-42. [Crossref]

35. Annuzzi G, Bozzetto L, Costabile G, Giacco R, Mangione A, et al. (2014) Diets naturally rich in polyphenols improve fasting and postprandial dyslipidemia and reduce oxidative stress: a randomized controlled trial. Am J Clin Nutr 99: 463-471. [Crossref]

36. Qin Y, Xia M, Ma J, Hao YT (2009) Anthocyanin supplementation improves serum LDL- and HDL-cholesterol concentrations associated with the inhibition of cholesteryl ester transfer protein in dyslipidemic subjects. Am J Clin Nutr 90: 485-492.

37. Zern TL, Wood RJ, Greene C, West KL (2005) Grape polyphenols exert a cardioprotective effect in pre- and postmenopausal women by lowering plasma lipids and reducing oxidative stress. J Nutr 135: 1911-1917.

38. Pal S, Ho N, Santos C, Dubois P, Mamo J, et al. (2003) Red wine polyphenolics increase LDL receptor expression and activity and suppress the secretion of ApoB100 from human HepG2 cells. J Nutr 133: 700-706. [Crossref]

39. Yao SL, Xu Y, Zhang YY, Lu YH (2013) Black rice and anthocyanins induce inhibition of cholesterol absorption in vitro. Food Funct 4: 1602-1608. [Crossref]

40. Gebhardt R (2003) Variable influence of kaempferol and myricetin on in vitro hepatocellular cholesterol biosynthesis. Planta Med 69: 1071-1074. [Crossref]

41. Sanchez-Moreno C, Cano MP, de Ancos B, Plaza L (2004) Pulsed electric fieldsprocessed orange juice consumption increases plasma vitamin $\mathrm{C}$ and decreases $\mathrm{F} 2$ isoprostanes in healthy humans. J Nutr Biochem 15: 601-607.

42. Sanchez-Moreno C, Cano MP, de Ancos B, Plaza L (2006) Mediterranean vegetable soup consumption increases plasma vitamin $\mathrm{C}$ and decreases F2-isoprostanes, prostaglandin E2 and monocyte chemotactic protein-1 in healthy humans. $J$ Nutr Biochem 17: 183-189.

43. Kaliora AC, Dedoussis GV, Schmidt H (2006) Dietary antioxidants in preventing atherogenesis. Atherosclerosis 187: 1-17. [Crossref]

44. Wang TT, Edwards AJ, Clevidence BA (2013) Strong and weak plasma response to dietary carotenoids identified by cluster analysis and linked to beta-carotene 15,15'-monooxygenase 1 single nucleotide polymorphisms. J Nutr Biochem 24: 15381546.

45. Ros E, Martínez-González MA, Estruch R, Salas-Salvadó J, Fitó M, et al. (2014) Mediterranean diet and cardiovascular health: Teachings of the PREDIMED study Adv Nutr 5: 330S-6S. [Crossref] 
Bacchetti T (2016) Correlation between plasma levels of carotenoid and oxidized low density lipoproteins: A short human intervention study

46. Hulthe J, Fagerberg B (2002) Circulating oxidized LDL is associated with subclinical atherosclerosis development and inflammatory cytokines (AIR study). Arterioscl Throm Vas 22: 1162-1167.
47. Meisinger C, Baumert J, Khuseyinova N, Loewel H, Koenig W (2005) Plasma oxidized low-density lipoprotein, a strong predictor for acute coronary heart disease events in apparently healthy, middle-aged men from the general population. Circulation 112: 651-657.

Copyright: (C2016 Bacchetti T. This is an open-access article distributed under the terms of the Creative Commons Attribution License, which permits unrestricted use, distribution, and reproduction in any medium, provided the original author and source are credited. 